\title{
Cuadros del imaginario colonial en Lima la horrible de Sebastián Salazar Bondy
}

\author{
Pictures of Colonial Imaginary in Sebastián Salazar Bondy'book \\ Lima la Horrible.
}

\author{
Santiago López Maguiña \\ Universidad Nacional Mayor de San Marcos, Lima, Perú \\ Contacto: slopezm@unmsm.edu.pe \\ http://orcid.org/0000-0001-5116-2657
}

\section{Resumen}

Lima la horrible de Sebastián Salazar Bondy, libro emblemático de los años sesenta del siglo pasado, recientemente vuelto a editar, tiene como objeto desmitificar el mito según el cual Lima es una ciudad colonial. Con este propósito, el autor iconiza en distintos cuadros cómo es visualizado el mito y compone escenas visuales de su reverso imaginario. Este artículo destaca los principales elementos de tales cuadros y algunos de sus principios de unificación o de totalización.

\section{Palabras claves}

Arcadia colonial, mito colonial, perricholismo, criollismo, imaginario, inconización, cultura peruana, semiótica.

\begin{abstract}
Lima la horrible one of Sebastián Salazar Bondy, emblematic book of the sixties of the last century, recently reissued, aims to demystify the myth according to which Lima is a colonial city. In this purpose the author iconises in different pictures how the myth is visualized and composes visual scenes of his imaginary reverse. This article highlights the main elements of these tables and some of their principles of unification or totalization.

Keywords: Colonial Arcadia, colonial myth, perricholism, criollismo, imaginary, unconventional, Peruvian culture, semiotics.
\end{abstract}

Recibido: 11.06.17 Aceptado: 26.09.17

\section{Introducción}

Este es un análisis inicial hecho a propósito de la reciente edición de Lima la horrible de Sebastián Salazar Bondy, polémico libro aparecido en 1964, como homenaje a los 50 años de su publicación y gracias al empeño de Alejandro Susti, que ha cuidado la edición y ha escrito el interesante e informativo prólogo 
(Salazar Bondy, 2014). Las líneas que siguen se inscriben en los marcos de un proyecto de investigación que estudia la iconicidad (Bordron, 2011, pp. 145-175) de los estereotipos más importantes de la cultura peruana, y que se desarrolla con el apoyo del Vicerrectorado de Investigación de la Universidad Nacional Mayor de San Marcos.

Lima la horrible se propone desmitificar la imagen que se ha construido de la capital peruana y los valores inscritos en ella. Es explícito el propósito de descubrir que las representaciones hechas de Lima, la capital del Perú, son falsas respecto a la realidad. Es explícito también que sean representaciones. Lima la horrible, de Sebastián Salazar Bondy, es un libro animado por la intencionalidad de deconstruir el imaginario prevaleciente en los años sesenta sobre esa ciudad. Es de destacar que se publica en 1965, tres años antes del golpe militar que poco más tarde inició la reforma agraria y echó a andar diversas transformaciones que contribuyeron a debilitar de manera importante la hegemonía de la oligarquía agrícola, minera y financiera que dominaba en el Perú, la misma que ha recuperado posiciones después de las reformas neoliberales de Alberto Fujimori. En Lima la horrible se habla de un Perú predominantemente colonial, aunque ya afectado por notorios cambios cosmopolitas. Este es un país que, en el campo de la cultura, se resiste a integrarse en los procesos de modernización que experimentaban algunos vecinos. $\mathrm{O}$, echando mano a las sistematizaciones de Aníbal Quijano (2014, pp. 285-326), se fortalece en su empeño de mantenerse colonial como efecto de su inserción en el sistema capitalista global. Lo colonial es causa del capitalismo financiero. Pero si seguimos el hilo argumental de Sebastián Salazar Bondy se dirá que más bien es un país dominado por una casta blanca de origen español que persiste en conservar formas de vida coloniales, a pesar de la presencia cada vez más intensa y extensa del capitalismo.

\section{Dimensión plástica: cuadros de la Arcadia colonial}

La persistencia colonial en Lima tiene, en el ensayo de Salazar Bondy, una dimensión plástica e icónica muy explícita. Aparece como un "espejismo" (53). Es presentada como una "estampa" (53) de "abundancias y serenidades" (53), 
e idealizada como una "Arcadia" (53). La representación cuaja en el siglo XVII en "imágenes de Indes Galantes" (54) y es recogida por Ricardo Palma, "el más afortunado difusor de aquel estupefaciente literario" (54), de cuya pluma surge una "galería" en la que aparecen "cortesanos respetuosos y respetables" (54), un "fabuloso decorado de sus representantes regios, de sus coquetas aunque púdicas mujeres, de sus clérigos menos licenciosos que concupiscentes, todos desaprensivos en cuestiones profanas, jamás en cosas de dogma o teología" (54).

La realidad de Lima y de los limeños es recogida, desde un punto de vista principalmente visual, en cuadros que componen un mundo armónico, homogéneo y sereno. En las pinturas literarias de Palma se presenta un equilibrio particular, que hace congruente la coquetería con la pudicia de las mujeres, el libertinaje con la concupiscencia de los religiosos. Ofrece una ambivalencia que caracteriza tanto la iconicidad como el simbolismo colonial del que se tratará líneas abajo.

\section{Signos y enunciados de la Arcadia colonial}

Lima la horrible destaca muchos signos de lo colonial. Los más marcados son los que ostentan las "grandes familias" dominantes: "cuadros de pintura cuzqueña", calificados de "piadosos"; "casas de estilo neocolonial de mobiliario barroco"; “emparentamientos endogámicos"; "falsos y legítimos escudos”; "pruritos de señorío bien servido"; "hispanismo meramente tauromáquico y flamenco"; "eminencia [...] chapada de memorias genealógicas" (59). Esta relación registra figuras y predicados de la Arcadia colonial que se disponen en cuadros. Son figuras concretas, como las pinturas de la Escuela cuzqueña, las casas, el mobiliario, los escudos, la fiesta taurina, el baile flamenco. Son también figuras abstractas como los "pruritos de señorío bien servido", o los “emparentamientos endogámicos".

Sin mucho análisis se detecta en ellas la representación de una forma de vida pretenciosa, que busca una posición dominante, que afirma exclusividad mediante sus alardes de nobleza y de sus ancestros distinguidos, y que al mismo tiempo es frívola y superficial. La frivolidad aparece en los signos que dejan ver una predilección por lo hispano que se limita solo al gusto por los toros y la afición al baile flamenco. En cambio, más serios y decisivos son los signos que expresan 
la orientación endogámica de las alianzas matrimoniales: el deseo de formar una comunidad exclusiva y excluyente, solo integrada por individuos idénticos entre sí. Se precisa que el origen de los miembros de las "grandes familias" es hispano, aunque de manera accidental ellas pueden realizar matrimonios con personas de procedencia extranjera. Sobre este punto es de destacar que nunca un vínculo de ese tipo ocurre con personas de color, que son excluidas. Se entiende que se afirma como signo superior el color de la piel y el origen europeo en el orden de un sistema de castas. Salazar Bondy sostiene lo siguiente en una aclaración entre paréntesis: “[...] son dudosos, y en todo caso si los hubo, fueron excepcionales, los adulterios entre blancos y esclavos negros a que hizo mordaz referencia González Prada" (74). Es una cita que revela una voluntad aristocrática muy fuerte. Las "grandes familias" operan en su constitución de una manera selectiva.

Es de interés anotar que la ausencia de mención a las relaciones con indígenas puede hacer suponer que fueran incluso impensables o abominables. A lo largo del libro, la presencia de lo mestizo es importante, de lo que se puede desprender que las mezclas se producen a pesar de los esfuerzos de selección y que minan las representaciones coloniales.

Otros signos son las "carrozas doradas" donde se pasean presidentes y dignatarios nacionales y extranjeros, las que pretenden marcar la supervivencia del régimen virreinal y la prosapia española de la capital del Perú. Lo mismo se puede decir de la importante expresión "el puente y la alameda", dos de las obras más emblemáticas de la arquitectura limeña que aún estaban casi intactas en la década de los sesenta del siglo pasado; la última de ellas, la alameda, fue construida durante la época del virrey Amat para halagar a su amante, la Perricholi, quien representa a la mujer plebeya que asciende socialmente y consigue hacerse de una posición ventajosa sin haberse casado, hecho escandaloso a fines del siglo XVIII.

Los principales signos pertenecen a una iconicidad visual, con excepción de los "valses criollos" y el baile flamenco, que ofrecen una expresividad sonora y cinética. La mayoría son figuras corporales, heráldicas, arquitectónicas, gubernamentales, festivas, anecdóticas que indican, iconizan y simbolizan una forma de vida ligada a las esferas de poder y de privilegio en el periodo colonial, más que 
una vinculación con la metrópoli española. Esos signos se disponen de acuerdo con los esquemas perceptivos que las clases altas y que los intelectuales limeños han fabricado; además, se relacionan con la obstinación por preservar un modelo de vida implantado en el periodo virreinal, antes que imitar los existentes en España, de cuya cultura apenas han asimilado el gusto por las corridas de toros y por el baile flamenco. El españolismo de esos actores es, según Salazar Bondy, superficial y fingido. Carece de autenticidad. En cambio, los signos indican una preferencia por la forma de vida colonial que toma consistencia en el siglo XVIII, en época del virrey Amat, cuando se realizan las principales obras arquitectónicas que hoy son expresiones saltantes de la mencionada forma de vida, cuyas persistencias más importantes se dejan ver en la organización jerárquica de los distintos estamentos sociales, del Estado, de la educación, de la Iglesia, de la familia, con la que se generan valores exclusivos y aristocráticos.

\section{Enunciación e ideología: las formas de vida de la Arcadia colonial}

Los signos de lo colonial y los enunciados que los organizan se disponen por doquier y desde distintas fuentes: “[...] en los labios de los mayores se repiten rutinarias las consejas coloniales, en las aulas se repasan los infundios arcádicos, en las calles desfilan las carrozas doradas del Gobierno y en los diarios reaparecen como un ciclo ebrio las elegías del edén perdido" (56), escribe Sebastián Salazar Bondy. Se transmite la experiencia de prácticas que si bien pertenecen al pasado, al mismo tiempo se persiste en encajarlas en el presente, en mantenerlas vivas hoy. "Cantamos y bailamos 'valses criollos', que ahora se obstinan en evocar el puente y la alameda tradicionales, y se imprimen libros de anécdotas y recuerdos de aquellos que José Gálvez bautizó como 'la Lima que se va'” (56).

Las imágenes quiméricas han logrado instalarse en Lima y entre los limeños de una manera consistente y firme: "la multitud ha ingerido sin mayor recelo durante más de una centuria innumerables páginas de remembrantes doctores con la respectiva dosis alucinógena" (54). Se ha formado una creencia. Sebastián Salazar Bondy sentencia al respecto: "[...] estamos cómodamente sumidos en el congelado esquema de una quimera" (55).

El tipo de creencia que funda la forma de vida colonial es ficticia. Sala- 
zar Bondy la llama mítica y ha sido explícitamente fabricada para sustentar una posición de supremacía, que tanto el pueblo sometido como sus creadores han asumido. Ella se sintetiza en el enunciado de que la época colonial fue una etapa idílica, de concordia y de bienestar; una edad de oro cuyos valores principales, la religión, las jerarquías sociales, el recato, el respeto por el superior, etc., aún siguen vigentes. Los limeños, por eso, viven enganchados en el pasado. Se ha conseguido que este tiempo sea un objeto de atracción intensamente fuerte. Mucho más, se ha conseguido hipnotizar con el pasado a los limeños, al punto que ya no tienen escapatoria. Se ha instalado "en todas partes, abrazando hogar y escuela, política y prensa, folklore y literatura, religión y mundanidad" (56). Ha penetrado la cultura popular. Es un sistema de percepciones, de sensaciones y de conceptos incorporados en la conciencia de los limeños, que contiene las pautas de conducta “para el Pobre Cualquiera que ansía ser Don Alguien” (56). En función del léxico sociológico y marxista de los años setenta, difundido por el magisterio de Louis Althusser (1968, pp. 102-151), lo colonial se diría es la ideología que une como argamasa los distintos componentes del edificio social. Ve dibujarse una serie integrada por las siguientes funciones: a) formación de la Arcadia colonial, la cual se presenta como una expresión plástica; b) inculcación de ese imaginario, principalmente visual, en toda la población; c) conversión en creencia y en conducta.

Si se considera la conducta como práctica regida por el poder y por el querer, es decir, como un querer-poder-hacer (Fontanille, 2014, pp. 147-149), es entonces práctica dominada por el deseo que la convierte en fantasía; es construcción y actuación mediante las cuales se vive una existencia de realizaciones alucinatorias de deseos. El limeño, en este sentido, vive la ilusión de ser parte del mundo colonial.

La serie planteada es consecuencia, por otro lado, de una enunciación en cuya praxis se halla implicada la sociedad limeña en su conjunto. Hay que apuntar, sin embargo, que en el centro de la praxis enunciativa se ubican las "grandes familias", que otros autores denominan oligarquía. También se encuentran en el centro los "remembrantes doctores": académicos, sin duda, que escriben sobre Lima y su historia. Los principales actores del poder económico, del poder aca- 
démico y del poder político constituyen el cuerpo enunciativo de la Arcadia colonial. De ese centro se desplaza la fuerza y la intencionalidad de la enunciación hacia todos los autores e instituciones encargadas en este caso de reproducir e inculcar las creencias y las prácticas de la ideología colonial, lo que Louis Althusser denomina aparatos ideológicos de Estado: el hogar, la escuela, la política y la prensa, el folclore y la literatura, la religión y la mundanidad. La irradiación alcanza a las "mayorías" (55), a “ toda la cultura popular" (56). Llega a incorporarse al "kitsch nacional" (56), ello es, a las formas del gusto que se alimentan de la incorrecta imitación de las formas de vida y prácticas propias de la semiósfera de las clases altas. Esto es capital: las formas de la Arcadia colonial llegan al punto de invadir las actuaciones propias del sector popular, y determinan la búsqueda de su mimetización con el poderoso. Los enunciadores no solo imponen imágenes, discursos, prácticas, sino también las prácticas de su imitación. Quienes asimilan el imaginario colonial lo hacen imitando la imitación. Hay un modelo que se imita y la forma en que se lo imita es una imitación. La mala imitación que es "kitsch nacional" es engendrada por quienes implantan el parangón a imitar.

\section{Dos cuadros de la Arcadia colonial: el perricholismo y el criollismo}

Un objeto-signo privilegiado de la Arcadia colonial es la "corte", lugar protocolar y ceremonial del virreinato que replica el modelo del reino español. Acceder a ella era, en tiempos de la colonia, un logro político y social soberbio. Equivalía a alcanzar el reconocimiento máximo de lo privilegiado. Por eso se desarrollan actuaciones propias de un culto, que implica una serie de prácticas rituales de ofrenda y de retribución. Uno imagina regalos que se hacen a cambio de prebendas que se reciben, bien retratadas en la narrativa de Julio Ramón Ribeyro, en especial en ese gracioso relato que es "El banquete". La "corte" es un espacio redivivo donde todo limeño "de sepa o no" (55) aspira a llegar. Es un lugar "del boato palaciego" (55), que sin duda hace referencia a los salones de la Casa gobierno. Sobre este punto Salazar Bondy plantea un símil. El ingreso en la "corte" es equivalente a las escenas en que Micaela Villegas accede a la cama del virrey Amat. La dama, llamada Perricholi con ironía y burla, no se sabe si por error en la escucha del acento catalán del representante real o por una derivación lingüística nativa, llega a la 
más alta esfera del poder gracias a sus encantos y habilidades seductoras. A sus destrezas en las artes de los rituales amorosos. En el dar y el recibir de la vida erótica. De allí procede el perricholismo, término acuñado por Luis Alberto Sánchez para designar la aspiración de "todo individuo y la sociedad limeños" (55) ha ser incluido entre los convidados frecuentes del Palacio de Pizarro, donde si bien habita un presidente republicano, desde hace más de 140 años (hoy serían 186 años), se imagina como un virrey español. La expresión remite al sentido de vida de todo limeño notable: conquistar el poder, después de un recorrido que comienza "en el puesto público", siguen en "la diputación o el capitulerismo electoral" (56), y debe terminar cerca al Jefe de Estado. Es el recorrido del intercambio de favores.

La escena y la escenografía del perricholismo encuadran las prácticas que apuntan al acceso del poder, a lograr una posición selecta y exclusiva. Ellas son acompañadas y complementadas, a pesar de ser incongruentes entre sí, por las escenas y las escenografías del criollismo. El término criollo, según Salazar Bondy, que originalmente "fue el apelativo otorgado a los hijos de los africanos nacidos en América Latina (Inca Garcilaso de la Vega)" (63), luego tuvo una connotación subversiva, durante los años de la Emancipación. Se "llamaba así a los descendientes de los españoles que alentaban sentimientos de nacionalidad" (63). En “ciertas circunstancias equivale a 'mestizo de acá' (Martín Adán)” (63). En la actualidad, afirma Salazar Bondy, significa "limeño —o, por extensión, costeñode cualquier cuna, que vive, piensa y actúa de acuerdo con un conjunto dado de tradiciones y costumbres nacionales, pero, a condición, como lo sostiene François Bourricaud, de que no sean indígenas" (63). Por ello, concluye, criollo "resulta [...] sinónimo de costumbrista" (63).

Para Salazar Bondy, no obstante, en Lima se tiene "más costumbrismo que costumbres" (63). No existen prácticas establecidas a lo largo del tiempo que hubieran podido encarnarse en los cuerpos y desarrollarse de una manera natural. No se habría hecho física y espiritualmente parte de la actuación de los limeños. Serían, por tanto, costumbristas para designar un aparecer y no un ser. Sustancial y formalmente serían solo un alarde y la intención de dar consistencia a una forma de vida, no una efectiva persistencia. Solo una simulación. El criollismo no con- 
lleva por eso una auténtica identificación con las prácticas que la componen, que son casi todas las que integran la vida cotidiana. "Nuestro costumbrismo, escribe Salazar Bondy, es totalitario. Abarca cocina, música, arquitectura, danza, deporte, farmacopea, urbanismo, lenguaje, poesía y religiosidad. Y asimila, por el culto y la práctica, tanto al limeño viejo cuanto al recién venido" (63). Se suele decretar que el extranjero, ““[e]se gringo (o ese chino, o ese italiano) es muy criollo' [...] para dar a entender que el migrante adopta las principales costumbres tradicionales, las viandas o la música" (63). El calificativo criollo convierte en local o colorea de localismo a toda práctica a la que predica; "la literatura, la Navidad o la política" (64) se hacen de ese modo propias.

Este fenómeno expresivo carecería de importancia si no fuera generado y sostenido por el mito de la Arcadia colonial. Todas las costumbres se habrían constituido en la época colonial, a pesar de que la totalidad de los signos, las escenas y las escenografías de lo criollo no pueden ser reconocidos de esa procedencia. Es difícil demostrar

\footnotetext{
[...] que en las tabernas o huertas de la Lima del setecientos se comían anticuchos, se bailaban polquitas y se gritaban para alentar la fiesta, frases como ‘ $i$ Dale con el pie!’ y ‘ $¡$ Voy a ella!' - reputadas las quintaesencias de la alegría jaranista-, ni que en los besamanos áulicos los convidados fueran agasajados con pisco y chicha. (64)
}

Las figuras de la polquita, del pisco y de la chicha, junto con la de los anticuchos — que son subrayadas - remiten a totalidades imaginarias distintas. Los anticuchos son un plato andino que tiene también un ancestro africano; se prepara a la braza con carne de corazón de vacuno, cortada en trozos cuadrados, insertados en un pincho y cubiertos de un aderezo picante. La chicha es una bebida alcohólica hecha de maíz, de procedencia también andina, mientras que el pisco es un destilado de uva bebido desde su creación por campesinos y obreros, que no difícilmente ingresaba a los salones palaciegos, espacios propios del paraíso colonial. Mientras, la polquita es diminutivo de la polca, baile de origen europeo integrado en la esfera cultural limeña en el siglo XIX, cuando los aires musicales 
germánicos se pusieron de moda. Todos estos signos son incongruentes con el cuadro costumbrista correspondiente a la Arcadia colonial. No son parte de una esfera de afirmación jerárquica, constituida alrededor de valores de privilegio, cuyos principales signos son los escudos nobiliarios, las expresiones de la vida palaciega, el ejercicio del poder estatal, la corrida de toros, el color blanco de la piel, la apariencia europea.

Esas incongruencias son posibles, sin embargo, porque el mito lo permite: "el método de sus difusores es mezclarlo todo en un amasijo turbio e informe" (64). El significante criollo tiene el poder de integrar lo más heterogéneo y diverso, inclusive lo indígena, que es el conjunto con el que se diferencia para constituir su identidad. Las fronteras de esta categoría son movedizas y su identificación no es precisa, lo que sin duda se transmite en la irregularidad de su perfil. La imagen de lo criollo, por eso, se opone a la de lo indio, que parece nítida y definida. Lo criollo es polimorfo y cambiante, lo indio tiene una forma bien delimitada y fija. Esta percepción será discutida en otro artículo, en el que se verá que hay muchas imágenes de lo indio y en cambio será fundamental interrogar por las razones de su representación más o menos homogénea al menos hasta la década de 1950 , cuando se confrontan la representaciones que se hacen en las grande novelas indigenistas de Ciro Alegría y José María Arguedas. ¿Por qué hasta entonces no se percibieron las diferencias de la presencia indígena en la cultura peruana?

Lo criollo integra elementos contrarios y distintos que fuera de su propia esfera no podrían reunirse. Presenta una variedad de opuestos. Uno de ellos es la armonización entre la tapada (mujer cuyo atuendo con saya y manto servía para ocultar y revelar apenas sus encantos femeninos, usados para seducir), y la imagen de Santa Rosa de Lima "con sus duros cilicios y sus visiones, en nada parecidos a los lances de tercería de las encubiertas damas coloniales" (64). Apunta además Sebastián Salazar Bondy que son también criollas "la fiesta prostibularia y la procesión del Señor de los Milagros" (64).

Todas estas mezclas contradictorias tienen como fin "exaltar el régimen colonial" y "la opresión de que se nutría la opulencia dorada del antiguo régimen" (65). Para Sebastián Salazar Bondy, como se observa, la Arcadia colonial y una 
de sus formas constitutivas son producto de una fabricación realizada por unos actores que llama "quimeristas". Ellos "han sabido ladinamente compadecer, envolviéndolas en palabras vacuas y alucinantes, la concupiscencia con la fe, es decir, gula, lujuria y demás vicios con piedad cristiana, para contentar a los lúbricos señorones con la Santa Madre Iglesia y su vigilante pupila” (65). Dejando de lado la dimensión manipuladora que aparece en esta cita, interesa destacar el rasgo principal de lo criollo. Su constitución imaginaria heterogénea y su forma conjuntista. Es una configuración integrada por partes que no tienen características en común. En oposición, el perricholismo es una totalidad que Jean François Bordron llamaría aglomeración, en la medida en que todas sus partes tienen algo en común: la de llevar signos que apuntan al reconocimiento social, a la búsqueda de privilegios estatales por medios diversos, pero teñidos de una coloración erótica. A pesar de ello, ambas totalizaciones integran la composición de lo colonial limeño.

A este cuadro estético le sigue otra plasticidad también estética pero principalmente ética. Lo criollo tiene un componente de "inescrupulosidad y de cinismo" (66), que se concentra en el significante "vivez criolla" (66). Es el atributo de quien "venga de donde viniere, mediante la maniobra, la intriga, la adulación, la complicidad, el silencio o la elocuencia, se halla como un porfiado tente-enpie siempre triunfante" (66). El vivo es el rol modal de aquel que consigue lo que busca gracias a su ingenio para hacerlo de una manera ilícita y sin que por ello sea castigado, lo cual es motivo de exaltación e indulgencia. En sus distintas expresiones figurativas la viveza es una habilidad local formada en el periodo virreinal y se origina en la trapacería característica de los negocios "de terratenientes y de encomenderos, aristócratas en el papel, pero negociantes en la práctica" (67). Negociantes astutos para engañar a los clientes incautos. De tales prácticas se extendió por emulación luego esa conducta hacia el resto de la sociedad, en especial hacia la clase media formada "por una cutícula de burócratas, artesanos y militares" (67), situada encima de "los siervos indígenas, los esclavos negros, los braceros chinos y los subproductos de las mezclas" (67). La capa intermedia, blanca o semiblanca, identificada con la clase alta, no tiene otra manera de ascen- 
der que mediante la explotación y el engaño. Se deja entender que la viveza es el valor determinante para alcanzar posiciones de privilegio en la esfera formada por la Arcadia colonial. Acá es de destacar que el vivo criollo se distingue del pícaro español en el hecho de que este es una personaje de clase baja, mientras que el vivo es de clase alta y clase media. Es el que se mantiene en el poder y llega a él mediante el engaño y la estafa. El pícaro busca ascender y alcanzar la honra desde los bajos fondos. Apunta a salir de su estado de miseria y hambre gracias a su astucia y al dominio de las artes del engaño. Importa apuntar aquí que se trata del rol temático de un personaje marginal y singular, que pasa peripecias únicas e intransferibles. El vivo, en cambio, conforma un estereotipo que se extiende por la sociedad desde las clases altas, haciendo de sus prácticas y comportamientos una forma de vida generalizada. La viveza generada de acuerdo con el molde de vida colonial, se disemina en el imaginario de lo criollo hasta los estratos más populares. Lo criollo, queda claro, es término de una composición plástica de las más diversas prácticas de la forma de vida colonial, que se imponen y que son apropiadas desde el momento en que se les confiere líneas y colores locales. De esa suerte, lo criollo se despliega mediante signos, valores e imágenes procedentes del virreinato del siglo XVIII, consolidadas el siglo XIX, cuando se inscriben en crónicas y tradiciones escritas, $\mathrm{y}$, principalmente, adoptadas por el pueblo en los actos de sus prácticas. En especial, en el acto de su reconocimiento como hecho local, como hecho propio de su terruño. Es necesario decir, para terminar este punto, que dicha asimilación antes que pintar y teñir los signos de lo colonial - muchos extraños y extranjeros - con los colores territoriales de lo local, se trata de colorear y mimetizar con los colores de la sumisión a la cultura colonial.

\section{El reverso de la Arcadia colonial}

Los cuadros, las estampas, las galerías de la Arcadia colonial componen un espejismo. Forman imágenes ilusorias y quiméricas. En sus totalizaciones se dibujan y pintan personajes con nombre y con lugar en los archivos y en la memoria limeña. En su realización más acabada, tal como ocurre en las Tradiciones peruanas de Ricardo Palma, se presentan ante todo "cortesanos respetuosos y respetables" y "solo ocasionalmente héroes, nunca rebeldes ni libertadores" (54). Eso no signifi- 
ca que estos se hallen fuera del cuadro. Están allí, aunque no aparezcan. Son su reverso, el lado oculto o lo que no ingresa por incongruente. Salazar Bondy escribe:

La estampa que de [... la época colonial] en artículos, relatos y ensayos, se nos ofrece se conforma de supuestas abundancias y serenidades, sin que figure ahí la imaginable tensión entre amos y siervos, entre extranjeros y aborígenes, potentados y miserables, que debió tundir, por lo menos en su trasfondo, a la sociedad. (53)

La imagen de una Lima satisfecha y pacífica se contrapone con lo que se ve si se mira fuera del cuadro: entonces aparece una Lima conflictiva y descontenta, una ciudad de clases, jerarquías y desigualdades, de actores colectivos e individuales que se enfrentan.

La imagen unificadora es un supuesto, que presenta un reverso inocultable de separaciones. El lado visible del cuadro es un engaño y hay un lado no visible de separaciones y conflicto, una "fisura social" (53), que la consolidada ideología colonial no deja ver.

Para observar lo que no muestran los cuadros es suficiente ver fuera de ellos. Basta trasladar la vista a su exterior, salir de sus muros y desempeñar una praxis enunciativa, la de la crítica, que es muy difícil realizar, dada la intensión y extensión del implante ideológico de la Arcadia Colonial, la que ha llegado a hacer carne con los limeños. En términos fenomenológicos se ha ubicado en el centro la sensible recepción de percepciones y sensaciones, de donde emana el sentido (Fontanille, 2008, pp. 113-165). "Desmentir la Arcadia Colonial — escribe Sebastián Salazar Bondy - siempre será una penosa, ingrata tarea, pues la multitud ha ingerido sin mayor recelo durante más de una centuria innumerables páginas de remembrantes doctores con la respectiva dosis alucinógena" (54). Hacer la crítica de la Arcadia colonial tiene dos dimensiones: una es la lucha que uno mismo debe librar contra creencias instaladas en el interior, en el mí mismo, en los niveles más profundos del ser corporal. Otra es la lucha por librar a las muchedumbres de las alucinaciones arcádico-coloniales en las que están sumidas. Luchas porque hay resistencias, sin duda. Luchas también por desprenderse de una ilusión cuya 
consecuencia debería ser la decepción, el desencanto, el enfrentamiento con una falta de sentido y más aun con un vacío. Sebastián Salazar Bondy no expone explícitamente este efecto. Uno puede suponer que el hombre desencantado de la Arcadia colonial quedaría sin las imágenes y los discursos que dan sentido a su vida, sin la capacidad de reemplazarlos por otros. Sin la Arcadia colonial, el habitante limeño resultaría desorientado. De todas maneras, al mismo tiempo se entiende con claridad que la intencionalidad crítica es positiva, pues abre las vías para un reconocimiento auténtico.

Dos facetas pueden destacarse del reverso colonial. Una es el aspecto de las contradicciones no incluidas en las construcciones imaginarias de la Arcadia colonial, de esa supuesta Edad de Oro existente durante la época del virreinato. De hecho, como lo demuestra la historia, se produjeron enfrentamientos y conflictos que subyacen a la falsa imagen de un mundo armónico y tranquilo. La otra faceta aparece en la Lima del presente, la Lima moderna. La "quieta ciudad regida por el horario de maitines y ángelus, cuyo acatamiento emocionaba al francés Radiguet" (57), se "ha vuelto una urbe donde dos millones de personas se dan de manotazos, en medio de bocinas, radios salvajes, congestiones humanas y otras demencias humanas, para pervivir" (57). Sebastián Salazar Bondy describe someramente el cuadro de una ciudad en la que dos millones de seres "se desplazan 'abriéndose paso' $[. .$.$] entre las fieras que de los hombres hace el subdesarrollo aglomerante"$ (57). La contradicción, la violencia, el desorden eran parte de la vida colonial, que las imágenes de ella no recogen. Los mismos contenidos — con sus respectivas expresiones multiplicadas en sus efectos de perturbación, enfrentamiento, competición y polémica一, se muestran en el presente para desmentir las pretendidas representaciones de una actualidad que continúa reproduciendo un pasado inexistente, y que Sebastián Salazar Bondy contribuye a desmitificar en Lima la horrible.

\section{Referencias bibliográficas}

Althusser, L. (1968). La filosofía como arma de la revolución. Ciudad de México, México: Siglo XXI Editores. 
Bordron, J.-F. (2011). L'iconicité et ses imágenes. Études sémiotiques. París, Francia: Presses Universitaries de France.

Fontanille, J. (2008). Soma y sema. Figuras semióticas del cuerpo. Lima, Perú: Fondo Editorial de la Universidad de Lima.

Fontanille, J. (2014). Prácticas semióticas. Lima, Perú: Fondo Editorial de la Universidad de Lima.

Quijano, A. (2014). Colonialidad del poder y clasificación social. En Cuestiones y horizontes: de la dependencia histórico-estructural a la colonialidad/ decolonialidad del poder. Buenos Aires, Argentina: CLACSO.

Salazar Bondy, S. (2014). Lima la horrible. Prólogo de Alejandro Susti. Lima, Perú: Lápix Editores. 